\title{
Appraisal of Airborne Radioactive Effluent Sampling Systems-Comprehensive Analysis Format and In-Place Sampler Validation
}

L. C. Schwendiman

September 1976

Prepared for the Energy Research and Development Administration under Contract E(45-1)-1830 
NOTICE

Th:s report was prepared as an account of work sponsored by the Unized States Government. Neither the United States nor the Energy Research and Developmen: Administration, nor ariy of their employees nor any of their contractors, subcontractors, or their employees, makes aliy warranty, express or implied, or assumes any legal liability or responsibility for the accuracy, completeness or usefulness of any information, apparatus, product or process disclosed, or represents that its use would not infringe privately owned righis.

PACIFIC NORTHWEST LABORATORY

operated by

BATTELLE

for the

ENERCY RESEA.RCH AND DEVELOPMENT ADMINISTRATION

indier Contract EY-76-C-06-7830

Printed in the Lniced States of America

Avatiabie iroin

National Technica: Information Service

U.S. Department of Commerce

S285 Purt Roval Road

Springtield. Virginia 22151

Price: Printed Copy S___ Microfiche \$3.cc

ATIS

-Pages Selling Price

001-025 \$- 50

0.26-050 $\quad 55.00$

$05 ?-075 \quad 32.50$

076-100 $\quad 56.06$

$10 i \cdot 125 \quad \$ 6.50$

$126-131) \quad 57.00$

$151-175 \quad 57.75$

175-20:) $\quad 58.50$

$201-225 \quad 58.75$

$225-250 \quad \$ 9.09$

$257-275 \quad 510.09$

$276-300 \quad 510.25$ 
L.C. Schwendiman

Particulate \& Gaseous Waste Research ATMOSPHERIC SCIENCES DEPARTMENT

September, 1976

Battelle, Pacific Northwest Laboratories Richland, Washington 


\section{TABLE OF CONTENTS}

INTRODUCTION

Page

1

OBJECTIVE

TASK 1 -- Develop a Comprehensive Sampling System Analysis Format and Check List for Evaluating the Sufficiency of a Nuclear Facility Airborne Effluent Sampler

Scope and Purpose

Development

TASK 2 -- Develop and Demonstrate a Sampling System "Validation Package" and Accompanying Methodology For an In Situ Evaluation of the Adequacy of the Systen

Scope and Purpose

Progress During FY-1975, FY-1976

Tracer Gas

Particle Specification and Aerosol Generation

Intercomparison and Indicated Preferred Method

Dry Powder Dispensers

Liquid Droplet Dispensers Methods for Evaluation of Aerosol Sampling System Effectiveness 
BNWL-1921

\author{
APPRAISAL OF AIRBORNE RADIOACTIVE EFFLUENT SAMPLING \\ SYSTEMS -- COMPREHENSIVE ANALYSIS FORMAT AND \\ IN-PLACE SAMPLER VALIDATION
}

\title{
INTRODUCTION
}

Radioactive particles and gases are generated in virtually a 11 processes involving radioactive materials; hence, stringent controls are placed on the quantity of radioactive materials which can be released to the atmosphere through normal ventilation exhausts. High efficiency air cleaning filters are the usual barrier to preclude the release of intolerable quantities of particles. Radioactive gases are trapped by adsorber beds such as charcoal, impregnated inorganic media, or cryogenic systems. Even with these barriers and trapping media, a small fraction of the particles and gases will be released, even under normal operating conditions.

In the event of an accident or other inadvertent incident an entireiy different release potential may occur. Fires, explosions, criticality incidents, or air cleaning failures could resuit in serious releases. The possibility of these serious events is, by careful designs and good work procedures and practice, kept to a very low value. Accident probability cannot be reduced to zero, and certain emergency preparedness instrumentation is required. $[1,2]$

The Nuclear Regulatory Commission requires that airborne and liquid radioactive streams released to the environment be monitored in such a way that the 1 icensee can demonstrate compliance with regulatory requirements such as 10 CFR Part 20, and the criteria set by the "as low as reasonably achievable" philosophy.

The means for demonstrating compliance with applicable airborne release limits consist of sampling and monitoring systems at or near the point of release to the environment. Sampling systems are sometimes designed and installed without the benefit of an objective assessment of the regulatory and technical requirements. Examples could be cited in which a sampling system could not possibly deliver an accurate sample due to failure to take into account the aerodynamic behavior of particles in the sampiing system. Frequently, the requirements of the system are not clearly stated, even if known. Designers and drafts- 
men responsible for construction drawings are often left to their own interpretation of the sampling requirement, either for the routine release or for the emergency situation.

Aerodynamic behavior of particles in sampling and transporting systems must be understood to a degree such that the sample obtained is representative in time and space. Frequently, the derodynamic particle size is not known and thus, conservative assumptions must be made in the estimates of line loss and other errors which are markedly a function of particle size and density. If known principles are understood and applied, a representative sample can be obtained, although sometimes requiring unusual designs.

The mechanics of sampling, as important as it is, is only one of the important steps in the total evaluation of the airborne release. Accurate assessment of the radioactivity in the collected sample requires procedures and counting equipment and appropriate calibration standards. Although this seems to be an obvious requirement, frequently filter samples are analyzed for radioactive constituents with inappropriate radioassay techniques and counters.

\section{OBJECTIVE}

In light of the concerns expressed in the foregoing INTRODUCTION, a study is being undertaken which has a major objective:

Develop and present information and tools useful in designing and evaluating airborne effluent samplers and monitors.

Two tasks are addressed in this report.

Task 1: -- Deve lop a comprehensive analys is format and check list for evaluating the sufficiency of a nuclear facility airborne effluent sampler.

Task 2: -- Develop and demonstrate a sampling system "validation package" and accompanying methodology for in situ evaluation of the adequacy of the system.

This document is a report on the progress made in FY-1976 toward these two tasks. In the following discussion, each task will be addressed separately. 
TASK 1

DEVELOP A COMPREHENSIVE SAMPLING SYSTEM ANALYSIS FORMAT AND

CHECK LIST FOR EVALUATING THE SUFFICIENCY OF A NUCLEAR FACILITY

AIRBORNE EFFLUENT SAMPLER

\section{Scope and Purpose}

The purpose of the sampling system analysis format is to provide a list of questions and statements in a sequence and format such that an existing sampling system may be appraised from a technical standpoint. Accurate responses to the questions and statements should provide the necessary information for providing reasonable assurance that the system can be evaluated to determine that it will fulfill its stated purpose. In concept, the analysis format and check list is primarily applicable to already installed systems. With such an analysis format and check list available, the user and system designers can better insure that each issue in the design of a system will be addressed.

An appendix is provided to permit a technical assessment to be made of the representativeness of a sample and the efficiency with which the particles in a sample will be delivered to the collector.

\section{Development}

The analys is format and check 1 ist herein presented was developed from consideration of the elements of the system and information needed to make a valid assessment. Although believed to be adequate in its present form, we solicit comment and constructive criticism for its improvement. 


\section{AIRBORNE PARTICULATES AND GASES SAMPLING SYSTEM ANALYSIS} FORMAT AND CHECK LIST

\section{Sampler Location and Physical Description}

A. Building number and name, sampler designation. State anticipated radionuclides in exhaust.

B. Ventilation component or exhaust to be sampled. (Engineering drawings, as-builts.)

C. Description. Brief description with good, understandabie sketch of ventilation system and sampler. Current engineering drawings. (Insure that actual system conforms to drawings.)

D. Specific information needed.

1. Air flow rate in stream sampled.

2. Velocity distribution at section sampled.

3. Dimensions of duct.

4. Location of sample withdrawal point(s) with respect to nearest fan, bend, transition, breeching, air filter.

5. Sampling system materials in direct contact with sampled air.

6. Inlet sample probe dimensions.

7. Bends in lines between probe inlet and collector media.

8. Horizontal delivery lines - lengths, dimensions.

9. Vertical lines - lengths, dimensions.

10. Design sampler flow rate. Velocity in the sampling probe inlet.

11. Is a manifold and secondary sample probe used? Describe.

12. Location and description of sample flow measuring device and recorder, if used. Calibration, or other confirmation of flow rate accuracy taking into account humidity, temperature, and pressure.

13. Provision for eliminating moisture condensation in sampling line.

14. Sample temperature measurement.

15. Measurement or knowledge of temperature and humidity of effluent exhaust air.

16. Description and location of sample pump or aspirator.

17. Are there any provisions for measuring radioactivity associated with different Darticle sizes? If so, describe. 
II. Sampler Collector Media and Support

A. Particulate Collectors.

1. Media - glass fiber filters, cellulose, membrane, etc.

2. Dimensions of filter.

3. Design face velocity.

4. Assumed filter efficiency, references.

5. Description of filter holder.

B. Iodine Collectors.

1. Media description (state whether charcoal, silver screens, silver impregnated adsorber, charcoal filter, other.)

2. Media cartridge description (depth, diameter).

3. Face velocity for nominal flow.

4. Assumed efficiency, references.

C. Noble Gas Collectors.

1. Media description.

2. If noble gas not collected on a bed, provide description of noble gas in situ measurements.

3. Assumed efficiency, references.

D, Tritium Collectors.

1. Media description.

2. Collector configuration.

3. Assumed efficiency, references.

III. Sampler Operation

A. Provide written procedure for start-up and operation of sampler.

B. Provide written procedure for shut-down and collector removal.

C. How are collectors protected in transport to counting room?

D. State sampling time.

E. Are checks made of equipment and flowmeter during the run? Describe. Are alarms of indicators showing pump failure incorporated in the system? How soon can corrective action be carried out? Emergency power in case of power failure?

F. Is visual appearance of collector recorded, such as color, wet, dry, torn, sound, etc.? 
G. How is filter or other collector identified.

IV. Measurement of Radioactive Constituents on Collector Media (Samples Assayed After Collection)

A. Sample removal processing.

1. Collector media sectioned?

2. Chemical processing, leaching, extraction?

B. Describe detector system used.

1. Alpha particle counter, beta particle counter, gamma detector, other? Describe.

2. Geometrical arrangement for counting radioactivity on collectors.

C. Describe counter operation.

1. Give time-length of count, or other index such as total counts taken.

2. State statistical quality controls on counting system. Describe calibration procedures for specific isotopes and total $\alpha, \beta, \gamma$ counting.

3. Show how error and confidence limit of sample count are calculated and expressed, taking into account the background of the counter, and length of count. State how "minimum detectable" quantity is determined.

D. Calculation of 24-hour release to the environment, or other reporting basis.

1. Define elements of calculation, and the formula used.

2. Show error estimate for each term in calculation and how determined.

3. Is an error range determined for the 24-hour release of radionuclides? If so, how is it determined, and what confidence level is used? For example, is the error based on the most significant error in the several elements of the determination, or is the error estimated taking into account propagation of errors in separate, several elements of the calculation.

4. State the minimum "detectable" 24-hour release, and state the confidence interval with such statements as ... "There is only 1 chance in 10 that a release twice this value will go undetected." Convert the release limit into equivalent concentration in the effluent stream sampled in $\mu \mathrm{Ci} / \mathrm{CC}$. Explain how the detection limit is determined. (Anticipated statistical fluctuations in the background count will provide one reference point for estimating detection sensitivity.) 
V. Records

A. State how sample results are entered into the official record of released radioactive materials, and the procedure for maintaining this record.

B. Describe format of this record.

The following section is the analys is format for the monitoring function of the sampling system. In general, sections I - $V$ are applicable to the constant monitoring function of a sampling system. Frequently, but not necessarily, the sampler fills a dual role of an inventory of the 24-hour release and a monitor. A detector is located in close proximity to the collector, and the counting rate or accumulated count is recorded at a point in a control room, or other frequently occupied space. Appropriate a Tarms are provided.

\section{Monitoring Function}

A. Description -- Describe the collector-detector installed in the system.

1. Geometrical arrangement of collector and detector.

2. Written and graphic description of pathway of gas and particles through the system. Drawings, sketches, etc.

3. Describe radioactivity detectors. (Whether $\alpha, \beta$, or $\gamma$, solid state, GM counters, sodium iodide, etc.) Discrimination provided to permit only selected radionuclides to be sensed?

4. Flow rate, if not included in IV.

5. Describe signal generated and how displayed. (Count rate instrument, scales, other integrating system. Is background automatically subtracted, etc.)

6. Emergency power activation in a power failure?

B. Response to radionuclides for which system is designed.

1. State whether total alpha particle, total beta particle, total gamma photon detector, or whether discrimination is provided for radiation type and energy.

2. State method for detector calibration.

a. Source used - certification, standardization.

b. Frequency (built-in checks, etc.).

c. Adjustment to predetermined limits? Discriminator setting, etc.

d. Linearity at "high" levels of release. Calibration under this circumstance. 
3. State dynamic range of the instrumentation.

a. Anticipated maximum rate of release during accident or other inadvertent releases.

b. System response at important action levels. Describe the release levels prompting various actions. State how and how often the monitor is functionally tested at the various release levels of concern.

4. State sensitivity of the system. Provide statement of minimum radioactivity detectable and support the statement in a discussion of background routinely experienced, the detector-collector geometry and intrinsic detection efficiency of the radiation sensor, the sample flow rate and time required to reach a stated level above background. State the result in terms of the release in $\mu \mathrm{Ci}$, which would be detected above background with a $90 \%$ probability. For the design sampling time between filter or other collector replacement, state the minimum detectable release rate and equivalent concentration $\mu \mathrm{Ci} / \mathrm{cc}$ in the effluent stream sampled.

C. Reliability

1. State whether a redundant monitor is provided.

2. Describe provisions for insuring that failure of any critical feature will be signaled.
a. Sample flow.
b. Detector components.
C. Charts.
d. Alarm circuits.

3. Describe the time sequence of actions to correct a monitor malfunction. Is the time required to restore the monitor to normal operation consistent with technical specifications or other 1 icensing requirement for operating the facility with continuous monitoring of effluents? Explain the rationale leading to current operating practice.

4. Describe preventive maintenance procedures which assure reliability.

a. Component functional tests.

b. Parts replacement program.

C. Spare parts and components availability.

d. Other. 
The last section of the Comprehensive Analysis Format, Section VII, Sampler System Criteria, is perhaps the most important section. It is placed at the end of the main sections in the present check list, since in the analysis of an already installed sampling or monitoring system, no reference need to be made to what the sampling system was intended to do. Once the information is developed in responses to the inquiries called for in the foregoing sections, the performance of the system is established or can be evaluated as shown in the Appendix.

If a sampling system performance is to be specified, then the system formally designed, a clear statement of criteria for the sampling or monitoring system is essential. Sampling systems are designed generaliy with an inferred or subjective criteria. It is the intent of Section VII, then, to prompt consideration of the important aspects and qualities of a sampling or monitoring system which need to be addressed in the early stages of the design.

\section{Sampling System Criteria}

A. Purpose of the Sampling System

State the primary and secondary purpose for the particular sampler system considered. Possible purposes are the following:

1. Provide a quarterly inventory of total curies of released radioactive particles and gases.

2. To demonstrate that the process or equipment is not changing adversely, thereby allowing higher releases to the atmosphere; or conversely, to show that process changes result in lowered release.

3. Although total release of gross radioactivity in a given (extended) time period is an important reason for sampling, measurements to show that allowed concentrations are not being exceeded over relatively short intervals may be required.

4. The sampling systems may serve a dual function of inventory during routine conditions and also monitoring for the inadvertent release situation.

5. The sampling system may provide information of physical and chemical properties of the radioactive material in the effluent. Special requirements for particle sizing may be necessary. 


\section{B. Sampler System Design Assumptions}

Having stated the purposes of the sampler installation, the one specifying detail sampler requirements must state his assumptions with appropriate justification. Important issues to be addressed are the following.

1. State the radionuclides in the effluent to be sampled.

2. State whether monitoring is required for specific nuclides, such as iodine-131, strontium-90, tritium, etc.

3. State whether collection and monitoring of a single radionuclide (gases) is to be accomplished by chemical separation or by using selected detectors and energy or particle discrimination.

4. State the maximum active particle size the system is to be designed to sample. (This is an important criteria and must be stated with a satisfactory rationale or justification.)

5. State the period of sampling for the stated purpose of sampling.

6. State the minimum detectable radioactivity to be measured in a stated period of time, within a confidence interval. (More than one statement will likely be necessary, depending on the purpose statement. For example, a long term sample may require a much lower flow rate than one which must give detectable responses within, say $0.1 \mathrm{hr}$.)

7. State, if one purpose of the sampler is to monitor during emergency conditions, the dynamic range of the sensors in the monitoring instrumentation, and speed of response to a large step input.

8. Describe the requirements of the continuous monitor-detector package, recording and alarm features compatible with response, sensitivity, and reliability. Address natural background problems.

9. State the collector media to be used. Give dimensions, pressure drop vs. velocity, susceptibility to failure in handling, resistance to moisture, corrosive gases present.

10. State the requirement for maintaining the sample air above the dewpoint, or other specification.

11. Place any necessary limitations on the materials of construction including the sample delivery lines.

12. Describe any limitations or constraints on servicing, maintenance, and operation of the system with respect to accessibility, weather protection, manpower requirements, etc.

13. Describe flow-measuring instrumentation requirements for the sample 
flow and the total flow. State requirements on location, range, calibration, restriction of gas flow, resistance to corrosion as required, cleaning, indicating and/or recording, etc.

14. State the overall accuracy to be demonstrated and maintained in reporting the total radioactivity released in a stated interval of time. Permissible error contribution from a 11 elements of the sampling system to be addressed and the acceptable error in the final reported rate or quantity of radioactive material discharged will be specified. (NOTE: Several statements may be required here since the allowed error will be a function of the level of activity released, the halflife of the radionuclides, and other characteristics. Considerable thought will have to be given the numeric values for this criterion.

Objective responses to the 14 criteria elements should allow a designer to proceed with assurance that the system designed will more nearly serve its intended role. Moreover, a check list such as this will prompt the person responsible for operation of the sampler and reporting the effluent release to address the important issues.

A specification not included in the criteria list is the performance criteria of the radiochemical laboratory processing the collected samples. Although implied in 14, a separate criterion for collector analys is should be developed. In finalizing the analysis format, consideration will be given to including radiochemical analytical laboratory requirements, or at least an entry requiring a careful analysis of radiochemical methods to be used. 
TASK 2

DEVELOP AND DEMONSTRATE A SAMPLING SYSTEM "VALIDATION PACKAGE" AND ACCOMPANYING METHODOLOGY FOR AN IN SITU EVALUATION OF THE ADEQUACY OF THE SYSTEM

\section{Scope And Purpose}

Although application of good sampler design principles will help provide an accurate sample of particles from a gas stream according to certain criteria, confirmation that in use a sampling system is in fact delivering a valid sample to a collector is very desirable. Some features of even well-designed sampling systems do not lend themselves to empirical or theoretical analysis. Inlet losses as a function of main stream turbulence and nozzle geometry have not been adequately addressed. Neither have deposition losses in curved sampling tubes received enough attention. Operational conditions such as determination of the aliquot size being taken from the main stream, the ratio of sampling rate to main flow rate cannot be as precise as one might wish.

A demonstration that a given sampling system is in fact, delivering a sample of the necessary accuracy and precision would check in aggregate the error in the sampling system. It is the purpose of this task to explore possible methods for demonstrating effectiveness of installed sampling systems. We here consider the concept of a "sampling system validation package".

A sampling system validation package in concept is an easily used tracer gas and particle generator which will be used to inject known quantities of an easily measured gas and an accurately known quantity of particles into a flowing air strean or stagnant volume sampled by the system to be validated. A known quantity of the gas would be injected at a point upstream of the sampling point. The injection point could be the downstream side of the last filter bank, or at a point upstream where mixing would be complete by the time the gas reached the sampling point. The degree of mixing would be determined initially by the easily measured gas tracer which would be metered accurately into the duct at the injection point. The installed sampler operated in the routine way would be used to extract a sample and the sample then analyzed by an appropriate method. Once it was established that the mechanics of the sampling system and its mode of operation would insure a representative gas sample, the gas injector would be replaced carefully with a metered particle source of known size distribution. The sampler would be operated under design conditions and the injection rate determined from the sample. Good agreement would demonstrate that a representative sample would 
be obtained for an aerosol of known mean size.

Al though straightforward in concept, there are stringent requirements which must be realized for the system to be successful. Simplicity is highly desirable to avoid an unacceptable burden in applying the concept. Accuracy of generation rate of particles and the tracer gas either jointly or separately is mandatory. Particles and gas to be used must be selected with important criteria being the ease and reproducibility of the measurement method.

Progress During FY-1975, FY-1976

Various aerosol generation techniques were reviewed and the advantages and disadvantages of each considered for the application. A requirement matrix was set up and used to screen the various aerosol techniques chosen. Gas tracer systems were reviewed, and potential gases selected for further investigation. Inquiries were sent out and answers received regarding availability of preformed particles in the size range of interest.

In the following section the particular effort and conclusions from the work to date are presented.

\section{Tracer Gas}

1. Development of Criteria

The specification of a suitable gas for this purpose was developed as follows:

a. Stable and non-reactive with materials normally found in the system.

b. Not present in the system, or present at sufficiently low levels so that interference can be taken into account in a background sample.

c. Minor toxicity at concentrations required.

d. Readily sampled and measured reproducibly to $\pm 5 \%$, both at the inlet and at the sampling point.

e. Dilution in the systems under study between injection concentration and the fully mixed effluent gas will range from 1:3000 to 1:300,000.

f. Time to make a run should be less than 2 hours, preferably less than 1 hour. 


\section{Candidate Gases}

A nominal effort has been expended in investigating possible tracer gases for this application. Two gases showing promise and appearing to meet the specification were identified. One of these is ${ }^{85} \mathrm{Kr}$, the other is $\mathrm{SF}_{6}$, sulfur hexafluoride.

${ }^{85} \mathrm{Kr}$ contained in a cylinder of compressed air or nitrogen would be bled through a gas meter into the duct at the chosen injection point. At the sample point the sample gas would be drawn through a chamber containing a thin window GM Counter. The counts in a timed period would be recorded. At the greatest dilution anticipated, an injection rate of about $1 \mathrm{mCi} 85 \mathrm{Kr} / \mathrm{min}$ appears to be $\mathrm{mar}$ ginal for the specification. A facility exhaust system of $300,000 \mathrm{cfm}$ would thus contain about $0.003 \mu \mathrm{Ci}$ per $\mathrm{ft}^{3}$, or about $7400 \mathrm{~d} / \mathrm{m}$ per $\mathrm{ft}^{3}$. This would be a marginally measurable quantity in a flow through system for the $\pm 5 \%$ specification necessary. Greater quantities may be necessary for the higher total flows.

Some objections may be raised to the use of a radioactive long-lived gas; however, the risk of radiation exposure from these anticipated quantities of ${ }^{85} \mathrm{kr}$ is so small that these concerns may be allayed.

An important requirement of the ${ }^{85} \mathrm{Kr}$ system is that a method must be developed for standardizing the injected gas concentration with the detector/ collector and to measure the greatiy diluted ${ }^{85} \mathrm{Kr}$ in the sampled gas. Various means would be explored to perform accurate calibrations of the injected gas. Commercial gas dilution systems could achieve the 1:10,000 to 1:100,000 dilutions required with good accuracy. Accurate gas syringes could also be employed to prepare the dilutions required for detector calibration.

A second gas under consideration is sulfur hexafluoride, $\mathrm{SF}_{6}$. Non-toxic, non-reactive, readily available, and measurable at very low concentrations, this gas may be more versatile than $85 \mathrm{Kr}$. Qualifications and specifications for its use in this application would require further evaluation.

Other gases may be disclosed in further study which could prove equally advantageous, or superior.

\section{Particle Specification and Aerosol Generation}

The most appropriate particle for use in a validation system and the means for injecting the tracer particles into the air stream or volume to be sampled 
can be selected only after a specification of the desirable or necessary qualities of the particles. Attention was given to establishing desirable qualities of the particles, which are here discussed.

The particles to be delivered to the effluent air system must have several important characteristics. For a diagnostic evaluation of an installed sampling system, for example, more than one type and/or size distribution of particles would be desirable. Were it possible to simultaneousiy inject three easily differentiated particles each of a different size, then measure the sampled quantity of each by simple chemical or instrumental analysis, a rather straightforward measurement of sampler efficiency for the 3 different sizes of particles could be determined.

Although the multi-characteristic particle system would have merit, an initial effort is to specify a particle, a delivery system, and measurement methods. The necessary characteristics of the particles needed for the sampler validation are the following:

- Particle Size -- Particle size is one of the most crucial parameters in determining the effectiveness of a sampling system. It is important that the particle size (aerodynamic equivalent diameter) be representative of the particles to be sampled either routinely or in accident situations. Seldom is the effluent particle size and density known with any accuracy and its variation from time to time completely unknown. All nuclear facilities require very efficient air cleaning filters or other air cleaning equipment, hence one might assume that the only particles penetrating these units where very small -- sub-micrometer in size. There is evidence to show that as facilities age and corrosion products and accumulation of paint fragments, cement dust, etc., enter the systems, that the radioactive material is likely associated with particles larger than the size which might be expected to pass through a high efficiency filter. There is also the potential for gasket leaks, pin hole leaks, etc., which could result in particle size spectra which would include particles as large as $10 \mu \mathrm{m}$, perhaps even larger. The performance criteria for the sampling system being validated will materially influence the choice of the size spectrum of particles to be chosen. We believe that most systems can be validated with a spectrum of particles within a range of $0.1 \mu \mathrm{m}$ to $20 \mu \mathrm{m} \mathrm{AED}$. For a density of $4 \mathrm{~g} / \mathrm{cc}$, the actual diameter of a $20 \mu \mathrm{m}$ AED would be $10 \mu \mathrm{m}$. A requirement that a sampling system deliver a large fraction of $10 \mu \mathrm{m}$ density 4 particles to a collector is a challenging requirement even in very simple systems. 
Availability of well-characterized particles of several nominal aerodynamic median diameters would be desirable. Some diagnostic measurements could then be made. The use of near-monodisperse (narrow size distribution) particles would be desirable in some instances. In some low ventilation flow systems use of monodisperse particles may be practical, but in general, a polydisperse aerosol would be a more practical representation of particles expected in exhaust systems.

- Particle composition -- With the density-size distribution selected, the elemental and physical composition of the particles will have mandatory and desirable specifications as follows:

Toxicity -- The material used must not present significant hazards in its use or when released in the quantity anticipated.

Chemical Make-Up -- The material in the quantity used must be compatible with the ventilation system components and not jeopardize or interfere with the proper functioning of the nuclear facility. (Some elemental materials may be ruled out because of abnormally high cross-sections in reactor containment buildings, for example.) Relatively small quantities would be necessary, hence this requirement may not be difficult to meet.

This material may be chosen with a prime consideration being the ease and accuracy with which it can be determined in the samples collected. This specification will be addressed subsequently at greater length.

The material cannot be already present in the system, or will be present in levels not interfering with the measurements to be made.

Physical Strength, and Integrity -- The particles injected should maintain their integrity from the injection point to the sample collector. If humidity is high, non hygroscopic materials must be used. Particles should be single crystals, solidified spheres, or produced by comminution processes yielding particles of sufficient strength to not further be reduced in size by turbulence in the gas.

Electrical Properties -- Conducting materials would be preferred over non-conducting materials. Particles should be at charge equilibrium when delivered to the system. It may be necessary to provide an ion source to discharge particles prior to injection. (The nature of the electrical charge on nuclear process aerosols has not been measured, hence the requirement for electrical characteristic is somewhat arbitrary. When validating a system it might be desirable to use both charged and uncharged particles.) 
- Particle Formation and Injection -- Several particle formation modes have been considered in this study. Each is discussed briefly.

Grinding, Pulverizing, Ball Milling, Etc. -- A wide range of materials is available in finely divided state for various industrial uses. Many metal oxides, carbonates, silicates, sulfate, prepared commercially as paint pigments, fillers, etc., are available as dry powders. Several may meet the specifications with respect to particle size, etc. Fluorescent pigments such as ZnS may have merit for this application.

Condensation, Solidification of Molten Materials -- Particles are produced by a variety of condensation processes. Latex spheres are produced in 1iquid systems such that great uniformity is achieved. Metallizing "guns" produce a mist of metal particles which on condensation are largely spheres. The sintered metals industry requires tons of various powders which are produced in several ways but to a large extent by condensation or solidification of sprayed molten metal in the appropriate atmosphere.

Aspiration of Solution -- Sma11 droplets of solution containing soluble or suspended solids can be aspirated using various nebulizers. Upon drying, the droplet leaves a particle of the contained material. The particle size is determined by the initial concentration of the drop and size of the drop. Drops may be formed by delivering liquid to a spinning disk or by liquid jets which can be broken up in various ways, such as by vibrating the jet or orifice. Aspiration or other injection and drying of droplets of appropriate solution, should be seriously entertained for particle sampler validation. Generation rate is quite low, but choosing the solute such that good sensitivity may be achieved in the measurement should allow good accuracy at low generation rates. There is no question, however, that the equipment requirements and controls which would be necessary would be more complex and difficult than for a preformed particle test.

Intercomparison and Indicated Preferred Method

In Table I the several choices of aerosols and mode of formation are presented as an overview of some of the incentives to select one over another. After considering the various modes of formation, generation, and detection of test aerosols, we feel that dispensing dry, well characterized particles at a constant rate with measurement by gravimetric methods would hold the greatest promise for a relatively simple particle sampler validation "package". For diagnostic work, 
$\underline{\text { TABLE I }}$

SOME CANDIDATE METIODS AND MATERIALS FOR VALIDATING PARTICLE SAMPLING SYSTEMS

Formation or Generation Mode

Break up of Iiguids con taining a readily meascompound
Mechanics of

\section{nerosolization}

spinning disc

vibrating orifice

Uranine (soditum

salt of Fluorescein

Rhodamine, etc.

\begin{tabular}{|c|c|c|c|c|c|c|}
\hline & $\begin{array}{l}\text { Collison } \\
\text { Atomizer and } \\
\text { Similar Nebu- } \\
\text { lizers }\end{array}$ & (Same as above) & $\begin{array}{l}\text { Fluorimeter } \\
\text { Colorimetric } \\
\text { Flame photometry. } \\
\text { Atomic Absorp. }\end{array}$ & $1 \mu \mathrm{m}$ to $5 \mu \mathrm{m}$ & Polydisperse & $\begin{array}{l}\text { Difficult to maintain } \\
\text { constant output and } \\
\text { character of par- } \\
\text { ticle }\end{array}$ \\
\hline \multirow{4}{*}{$\begin{array}{l}\text { Dispensing } \\
\text { of pre- } \\
\text { formed par- } \\
\text { ticles }\end{array}$} & \multirow{4}{*}{$\begin{array}{l}\text { Transfer in a } \\
\text { stream of de- } \\
\text { livery air } \\
\text { using various } \\
\text { dispensers }\end{array}$} & Glass spheres & Gravimetric & $\begin{array}{l}\text { Medium but } \\
\text { adequate }\end{array}$ & $\begin{array}{l}\text { High integrity } \\
\text { particles. } \\
\text { Readily sized. }\end{array}$ & $\begin{array}{l}\text { Insulating spheres, } \\
\text { may have high } \\
\text { charge }\end{array}$ \\
\hline & & Metal powders & $\begin{array}{l}\text { Gravimetric } \\
\text { Colorimetric } \\
\text { Atomic Absorp. } \\
\text { Flame Photom. } \\
\text { Various Others }\end{array}$ & $\begin{array}{l}\text { Can select } \\
\text { a very sen- } \\
\text { sitive } \\
\text { method }\end{array}$ & $\begin{array}{l}\text { Wide choice of den- } \\
\text { sities. Particles } \\
\text { will have strength, } \\
\text { integrity. Are con- } \\
\text { ductors, non- } \\
\text { hygroscopic. }\end{array}$ & $\begin{array}{l}\text { Particles may have } \\
\text { too large particle } \\
\text { size range. Some sel } \\
\text { ections may be } \\
\text { necessary. }\end{array}$ \\
\hline & & $\begin{array}{l}\text { Pigments, oxides, } \\
\text { sulfides, carbon- } \\
\text { ates, fluorescent, } \\
\text { phosphorescent, } \\
\text { crystals. }\end{array}$ & $\begin{array}{l}\text { Gravimetric and } \\
\text { a wide ranye of } \\
\text { sensitive methods. } \\
\text { Colorimetric, } \\
\text { Fluorimetric, } \\
\text { Photometry, etc. }\end{array}$ & $\begin{array}{l}\text { Most com- }<1 \text { to }>20 \mu \mathrm{m} \\
\text { pounds once } \\
\text { solution can } \\
\text { be detected } \\
\text { with adequate } \\
\text { precision and } \\
\text { sensitivity. }\end{array}$ & $\begin{array}{l}\text { A wide range of den- } \\
\text { sities to choose } \\
\text { froin. Particles } \\
\text { would be physically } \\
\text { acceptable in most } \\
\text { cases. Some are NBS } \\
\text { standards. }\end{array}$ & $\begin{array}{l}\text { Some compounds may } \\
\text { be toxic - would } \\
\text { have to be selected } \\
\text { carefully. Also, sone } \\
\text { may be hygroscopic. }\end{array}$ \\
\hline & & $\begin{array}{l}\text { Minerals, natural } \\
\text { dusts; l imestone, } \\
\text { feldspar, clay. } \\
\text { sand dust, etc. }\end{array}$ & $\begin{array}{l}\text { Same, but are not } \\
\text { pure conipounds, } \\
\text { hence more dif- } \\
\text { ficult to anal- } \\
\text { yze by chemical } \\
\text { methods. }\end{array}$ & $\begin{array}{l}\text { Methods could }<1 \text { to }>20 \text { un } \\
\text { be adequately } \\
\text { sensitive. } \\
\text { but with } \\
\text { greater prep- } \\
\text { aration for } \\
\text { analysis in } \\
\text { some cases. }\end{array}$ & $\begin{array}{l}\text { Some avallable as } \\
\text { NBS reference stand- } \\
\text { ards. Non-reactive. } \\
\text { adequate strength. }\end{array}$ & $\begin{array}{l}\text { Complex, mixtures, } \\
\text { some development to } \\
\text { demonstrate appli- } \\
\text { cation. Gravimetric } \\
\text { method probably } \\
\text { adequate. }\end{array}$ \\
\hline \multirow[t]{2}{*}{$\begin{array}{l}\text { Condensation } \\
\text { processes }\end{array}$} & $\begin{array}{l}\text { Condensation } \\
\text { in gas phase }\end{array}$ & $\begin{array}{l}\text { Tributyl } \\
\text { phosphate }\end{array}$ & $\begin{array}{l}\text { Light } \\
\text { scattering }\end{array}$ & $\begin{array}{l}\text { Not suitable }<0.5 \mu \mathrm{m} \\
\text { (since only in- } \\
\text { stantanenus } \\
\text { concentrations } \\
\text { rather than in- } \\
\text { tegrated quan- } \\
\text { tity can be de- } \\
\text { termined.) }\end{array}$ & $\begin{array}{l}\text { Could be used to } \\
\text { Insure sample being } \\
\text { delivered in gas } \\
\text { phase was same as } \\
\text { in bulk stream. }\end{array}$ & $\begin{array}{l}\text { Too small particle } \\
\text { size. Can't inte- } \\
\text { grate sample over } \\
\text { time. }\end{array}$ \\
\hline & $\begin{array}{l}\text { Condensation } \\
\text { in liquid } \\
\text { phase }\end{array}$ & Latex spheres & $\begin{array}{l}\text { Gravimetric or } \\
\text { possible radio- } \\
\text { metric, if } \\
\text { tagged. }\end{array}$ & $\begin{array}{lcc}\text { Probably not } & <0.5 \mu \mathrm{m} \text { to } \\
\text { sensitive } & 5 \mu \mathrm{m} \\
\text { enough. } & \end{array}$ & $\begin{array}{l}\text { Single size par- } \\
\text { ticle. }\end{array}$ & $\begin{array}{l}\text { Iow density. Expen- } \\
\text { sive to obtain and } \\
\text { standardize, not } \\
\text { conductive. }\end{array}$ \\
\hline
\end{tabular}


can be measured fluorimetrically at a level of $5 \times 10^{-10} \mathrm{~g}$ dissolved in $10 \mathrm{ml}$ water, a typical end solution. Assuming that twice this level could be read to $\pm 5 \%$ only $1 \times 10^{-9} \mathrm{~g}$ would be required on the filter. Thus, only $3.3 \times 10^{-11} \mathrm{~g}$ per minute would be collected for 30 minutes. If the sample aliquot of the total exhaust flow were $1 \times 10^{-5}$, the injection rate required would be only $3.3 \times 10^{-6}$ $\mathrm{g} / \mathrm{min}(3.3 \mu \mathrm{g} / \mathrm{min})$. This analys is suggests that the spinning disc or vibrating orifice may be useful as a diagnostic tool to determine sampling efficiency as a function of particle size. It also shows that the error may be more controlled by the accuracy of injection rates, which for gravimetric measurement were assumed to be made negligible.

\section{Dry Powder Dispensers}

During the course of this study descriptions were obtained from the literature of a wide variety of powder feeders. Some of the most promising were identified for demonstration in this study. Deagglomeration upon introduction to the air stream is one of the most crucial requirements. The nature of the particles used and the energetics of the injection system are important features and must be interfaced to determine the degree of deagglomeration. This must be demonstrated on the particles selected.

One promising particle dispensing system was fabricated as described in the literature. It has not yet been tested under the conditions for sampler validation. The system with greatest simplicity yet meeting other requirements would be of greatest value in this application. The particle dispensing system fabricated requires a metered air supply for operation, hence, should prove advantageous.

Various configurations have been used in which particles are delivered from a hopper onto a moving trough, then the trough passed below an aspirator. The air driven aspirator picks up the particles and delivers them uniformly to the desired point.

The Wright dust feeder and other systems have been considered in this study. Detailed experimental evaluation of these and other particle dispensing systems would be investigated in detail in a continuation of this study.

\section{Liquid Droplet Dispensers}

A variety of nebulizers were considered for possible application in this study and a short experimental scouting study conducted to determine the operating char- 
acteristics of two of the more promising systems. The first of these was the sonic nozzle of which three different nozzles were tested. The sonic nozzle employs a resonator cavity driven by compressed air. Liquid to be nebulized is forced into the air stream inside the cavity. The liquid stream is broken into a fine spray by the sonic vibrations and ejected as a plume with the expanding compressed air. The liquid stream consisted of either water, water-alcohol, or a dilute uranine-water-alcohol solutions, which when nebulized, quickly dries to solid uranine particles. In the scouting studies droplet size distributions were measured using an axially scattering spectrometer probe*. A beam of light from a He-Ne laser illuminates a centrally-located volume with cross section of $0.86 \mathrm{~mm}^{2}$. A silicone photo-diode detector senses the forward scattered light from particles passing through the sampling volume. A pulse height analyzer measures and records the scattered light intensity in memory channels. Four size ranges are selectable: $0.5-7.5,1-15.0,20-30$, and $30-45 \mu \mathrm{m}$.

Three commercially available nozzles were examined for their ability to break up a jet into very fine droplets. Knowing the droplet size and concentration of the nebulized solution would permit dry particle sizes to be determined.

These scouting studies showed that sonic nozzles can produce very fine droplets in high concentrations. During the many tests conducted it became apparent that a detailed, well controlled parametric follow-on study would be necessary to establish the controls needed for successfully applying these nozzles for a sampler validation source. One of the more promising nozzles was operated at $\mathrm{N}_{2}$ gas pressures of 60 to $90 \mathrm{psig}$, and liquid pressures of either 10 or $20 \mathrm{psig}$. Number median droplet size ranged from about 4 to $20 \mu \mathrm{m}$, but there seemed to be no correlation between mean size and gas pressure. The droplets ranged up to about $45 \mu \mathrm{m}$ in diameter.

A generator using one of the more promising nozzles was assembled in a configuration suitable for use in large ducts and demonstrated in a $2^{\prime} \times 2^{\prime}$ duct. The droplet plume extended about seven feet in free air. The configuration would provide an arrangement readily applicable. Considerable development and demonstration in various air exhaust systems will be needed.

Other medical application nebulizers were tested and showed to have promise in this application. A 7 imitation is the small dispensing rate which would require multiplexing several units to obtain the required particle concentration. Droplet size was consistent at about 2.5 to $4.5 \mu \mathrm{m}$, number median diameter, with a few particles as large as $40 \mu \mathrm{m}$.

* Particle Measuring Systems, Inc., Boulder, Colorado. 


\section{CONCLUSIONS}

A comprehensive analysis format has been developed for installed radioactive gaseous effluent sampling systems. It provides the necessary questions which when accurately answered should permit a good analysis of the sampling system and provide documentation for sampler system description, mode of operation, etc.

Feasibility was shown for the application of gases and particles in a "validation package which will permit a good physical demonstration of sampling systems. Preformed particles with gravimetric methods for measurement appear to have certain advantages, but further study, using available equipment, should be undertaken. Selected systems would be demonstrated under simulated and actual sampling situations. Detailed procedures would be developed.

\section{REFERENCES}

[1] J.M. Selby, et al. Technological Considerations in Emergency Instrumentation Preparedness -- Phase II-A: Emergency Radiological and Meteorological Instrumentation Criteria for Reactors, BNl:L-1635, Battelle-Northwest, Richland, Washington, May, 1972.

[2] B.V. Andersen, et a1. Technological Considerations in Emergency Instrumentation Preparedness -- Phase II-B: Emergency Radiological and Meteorological Instrumentation for Mixed Oxide Fuel Fabrication Facilities, BNIVL-1742, Battelle-Northwest, Richland, Washington, May, 1974. 
APPENDIX A

DESIGN CONSIDERATIONS AND CALCULATIONS

METHODS FOR EVALUATION OF AEROSOL SAMPLING SYSTEM EFFECTIVENESS 


\section{AEROSOL SAMPLING -- DESIGN CONSIDERATIONS}

INTRODUCTION

In addition to the various problems associated with any gas sampling system, an aerosol sampling system poses special problems which must be taken into consideration in order to guarantee meaningful results. This Appendix addresses three problems: (1) Selection of a sample or group of samples which adequately represents the total stream. (2) Removal of the sample with a minimum of bias. (3) Transport of the sample from the point where it is removed from the stream to the point where it is collected or analyzed.

The special problems associated with aerosol sampling are due mainly to particle inertia and to their tendency to stick to surfaces with which they come in contact.

\section{SELECTION OF REPRESENTATIVE SAMPLES}

If the stream to be sampled is perfectly mixed, i.e., of perfectly uniform composition, the selection of a representative sample presents no problem. In selecting a sampling location then, one should choose a point where the stream is well mixed. A good rule of thumb is that the samples should be taken at least 10 duct diameters downstream and 5 duct diameters upstream of any flow obstruction or directional change. There is evidence to indicate that even in a long, we11 mixed duct, particle concentration gradients may be found so that there is generally some risk to use only one sample probe even in a well mixed duct unless the duct is smal1, say less than 6 inches in diameter with turbulent flow. In a long vertical duct or stack, the concentration at a given radius from the center should become relatively uniform around the duct because of the symmetry of the system. If this is the case, then the sample probe can be set up in either of two ways: The sample probes can be designed to all draw at the same flow rate and then arranged so that each serves an equivalent annular area in the stack; or the probes can be spaced at equal intervals across the stack and the flow rate of each adjusted to be proportional to the annular area sampled. In most cases the first method will be preferable. For long well mixed horizontal ducts the same procedure should be used except that for very large particles or low flow rates the probes should be arrayed vertically rather than horizontally, because gravitational settling will tend to increase concentrations in the lower portion while depleting the upper portions. 
Unfortunately, it is not always possible to place the sample probes at least ten duct diameters downstream and five diameters upstream of flow transitions. Changes in flow direction cause the particles to move relative to the gas stream. Because of this, a non-uniform concentration can be expected immediately downstream of any flow transition which causes directional change. For a given flow, the velocity of a particle relative to the gas is proportional to the square of the particle's aerodynamic equivalent diameter (AED)*. For very small particles, then, very little effect could be expected but for larger particles a very uneven concentration could be produced by a flow obstruction such as a bend. For particles with $d_{p}$ less than about 1 or 2 microns, no significant concentration gradients would be expected under conditions typically found in ventilation systems. There are two cases, then, which may cause concentration differences within the stream likely to cause significant sampling errors: if larger particles are to be sampled after some kind of directional change, or if the stream has not been adequately mixed upstream of the sampling point. Inadequate mixing can be expected if the sampling point is close to the particle source, if two or more streams join directly upstream of the sampling point, or if the flow is not turbulent. While sampling under any of the conditions is not likely to ever be highly accurate, judicious design of the sampling system can often improve the accuracy. A velocity traverse should be made to determine proper placement and flow rate of sample probes.

REMOVAL OF THE SAMPLE Without BIAS

As the sample stream is withdrawn from the main stream in the duct, there will inevitably be some disturbance of the normal flow profiles. Since particles cannot follow exactly the flow of the gas it is desirable to minimize any changes in flow direction which may be caused by the probe. This can best be achieved by placing the sample probe so as to face directly upstream and by drawing the sample stream into the probe at the velocity of the approaching stream. This is commonly referred to as isokinetic sampling. Deviations from isokinetic sampling can cause considerable errors in sampling. One study found for instance that particles with an aerodynamic diameter of 6 to 7 microns were sampled at 40 to $180 \%$ higher than their true concertrations when the sampling rate was 0.3 of the isokinetic rate; when the sampling rate was 4 times iso-

*The aerodynamic equivalent diameter of a particle is defined as the diameter of a hypothetical particle of unit density (water) which would have the same settling velocity as the given particle. For spherical particles $A E D=d_{p} \sqrt{\rho}$ where $\rho^{\prime}$ is the particle's specific gravity, and $d_{p}$ the particle diameter. 
kinetic, the indicated concentration was less than $5 \%$ lower than the correct value. Some workers advocate sampling at considerably higher than isokinetic. Curves, tables and formulae are available to estimate errors from this source. $[2,3,4]$ We have chosen to use the correlation of Davies in this study. [5]

The correlation equation relates to the ratio of concentration of the sample to the actual concentration, $\frac{C_{s}}{C_{a}}$, with a term $\left[\frac{V_{a}}{V_{s}}-1\right]\left[\frac{2 S t k}{1+2 S t k}\right]$

$$
\frac{C_{s}}{C_{a}}=1+\left[\frac{V_{a}}{V_{s}}-1\right]\left[\frac{2 \text { Stk }}{1+2 S t k}\right] \text {. }
$$

In this equation:

$$
\begin{aligned}
C_{S}= & \text { concentration in the sample } \\
C_{a}= & \text { actual concentration in the stream } \\
V_{a}= & \text { actual velocity in the stream } \\
V_{S}= & \text { velocity in the inlet of the sample probe } \\
\text { Stk }= & \text { Stokes number, the ratio of twice the stopping distance } \\
& \text { to the nozzle inlet diameter. }
\end{aligned}
$$

Stokes' number is calculated from the expression:

$$
\text { Stk }=\frac{v_{a} d_{p}^{2} \rho_{p}}{9 \mu d_{0}}
$$

in which $d_{p}=$ diameter of the particle in $\mathrm{cm}$

$$
\begin{aligned}
\rho_{p} & =\text { density of the particle in } \mathrm{g} / \mathrm{cm}^{3} \\
\mu & =\text { viscosity of air in poise } \\
d_{0} & =\text { diameter of inlet nozzle in } \mathrm{cm} .
\end{aligned}
$$

For air at $70^{\circ} \mathrm{F}$ and 1 atmosphere, and for particles of density $4 \mathrm{~g} / \mathrm{cm}^{3}$ :

$$
\text { Stk }=5.022 \times 10^{-6} \frac{v_{a}\left(d_{p}\right)^{2}}{d_{0}}
$$

$v_{a}=$ velocity in the stream, ft./min.

$d_{p}=$ particle diameter in $\mu m$

$d_{0}=$ probe inlet diameter, inches.

Some example values for a 0.5 inch diameter probe iniet, various particle diameters and three velocities for sampling rates twice isokinetic and 0.5 isokinetic are given in Table A-I. 


\section{TABLE A-I}

EXAMPLE VALUES FOR THE SAMPLE BIAS FROM ANISOKINETIC SAMPLING*

Sampling Conditions $V_{\mathrm{a}}=100 \mathrm{ft} / \mathrm{min}, 1000 \mathrm{ft} / \mathrm{min}, 2000 / \mathrm{ft} \mathrm{min}$ $\rho_{p}^{\prime}=4$ $v_{s} / v_{a}=2, v_{s} / v_{a}=0.5$

\begin{tabular}{|c|c|c|c|c|c|c|}
\hline \multirow[b]{2}{*}{$\begin{array}{r}\text { Particle } \\
\text { Diam., } \mu \mathrm{m}\end{array}$} & \multicolumn{2}{|c|}{$\frac{C_{s}}{C_{a}}$ for $V_{a}=1001 / \mathrm{min}$} & \multicolumn{2}{|c|}{$\frac{C_{s}}{C_{a}}$ for $v_{a}=10001 / \mathrm{min}$} & \multicolumn{2}{|c|}{$\frac{C_{s}}{C_{a}}$ for $v_{a}=2000^{\prime} / \mathrm{min}$} \\
\hline & $\underline{\sqrt{a}}=2$ & $\begin{array}{l}V_{a}=0.5 \\
V_{s}\end{array}$ & $\frac{V_{a}}{V_{s}}=2$ & $\frac{V_{a}}{V_{s}}=0.5$ & $\underline{V_{a}}=2$ & $\begin{array}{l}V_{a} \\
\frac{V_{s}}{s}\end{array}$ \\
\hline 0.5 & 1.00 & 1.00 & 1.01 & 1.00 & 1.01 & 1.00 \\
\hline 1.0 & 1.00 & 1.00 & 1.02 & 0.99 & 1.04 & 0.98 \\
\hline 2.0 & 1.01 & 1.00 & 1.07 & 0.96 & 1.14 & 0.93 \\
\hline 5.0 & 1.05 & 0.98 & 1.33 & 0.83 & 1.50 & 0.75 \\
\hline 10.0 & 1.17 & 0.92 & 1.67 & 0.67 & 1.80 & 0.60 \\
\hline
\end{tabular}

Transfer of The Sample to The Point OF Collection

After the sample enters the probe, it must be transported to the point of collection. Small particles will stick to surfaces with which they come in contact, so that if the particles carried in the sample stream contact the wall of the probe or delivery lines they can usually be expected to stick there permanently. To achieve maximum accuracy in sampling it is always desirable to place the collecting or measuring device at or very near the sample removal point. However, practical considerations often require some compromise in this regard. The recommended method of sampling is to place the collector directly in the duct to be sampled. If an entry nozzle is required, it should be as short and straight as possible. This method has obvious drawbacks. The collected sample must be removed from the duct for analysis, often routinely, which may be difficult. In nuclear facilities continuous monitoring of the collected sampling may be required. Excessive background radiation levels inside the duct and other operational problems may make direct collection inside the duct extremely difficult if not impossible. If delivery lines of any kind must be used,care must be exercised in the design and operation of the system so that excessive deposition can be avoided. The following section gives information which can often be used to estimate the losses to be expected. 
Particle Loss by Deposition on Tube Walls

\section{a. Straight Tubes}

Several types of deposition may take place in straight tubes. Under laminar flow conditions deposition may be due to some combination of diffusion, gravity settling, temperature gradients (thermophoresis), diffusive vapor fluxes (diffusiophoresis), and electrostatic forces. Under turbulent flow conditions, deposition will occur due to eddy diffusion and turbulent impaction in addition to those forces listed for laminar flow. Thermal deposition will occur if a hot gas is sampled and allowed to cool by transferring heat to the delivery 1 ine wall. This effect will be small except for small particles $\left(d_{p}<\right.$ about $0.1 \mu \mathrm{m}$ ) and large temperature differences $\left(\Delta T>\right.$ about $150^{\circ} \mathrm{F}$ ). Diffusive vapor flux may cause deposition if vapors are allowed to condense on tube walls, this condition is undesirable for a number of reasons and should be avoided if possible. Ordinary diffusion will nearly always result in negligible particle deposition. Deposition due to electrostatic forces should be mitigated by use of conducting delivery lines. Gravity settling, eddy diffusion and turbulent impaction then remain as the most important causes of deposition under most circumstances.

For horizontal tubes and laminar flow, an analytical solution is available for the gravity settling problem. The ratio of outlet to inlet concentration for a given particle size is given by: [6]

$$
\begin{gathered}
C / C_{a}=1-\frac{2}{\pi}\left[2 Z \sqrt{1-Z^{2 / 3}}+\operatorname{arc} \sin \left(Z^{1 / 3}\right)-Z^{1 / 3} \sqrt{1-Z^{2 / 3}}\right] \\
Z=0.75 \frac{v_{t}}{V_{a}} \frac{L}{D} \text { (dimensionless) } \\
v_{t}=\text { terminal gravitational settling velocity } \\
V_{a}=\text { velocity in tube (1aminar flow conditions) } \\
L=\text { length of sampling line } \\
D=\text { diameter of sampling line }
\end{gathered}
$$

For air at $70^{\circ} \mathrm{F}$

$$
Z=2.4 \times 10^{-5} \frac{\left(\text { AED }^{\prime}\right)^{2} D^{2}}{Q} \frac{L}{D}
$$

* The terminal gravitational settling velocity for spheres falling in the Stokes' law region is:

$$
v_{t}=\frac{g d_{p}^{2}\left(\rho_{p}-\rho\right)}{18 \mu}
$$

$g=$ acceleration due to gravity

$d_{p}=$ particle diameter

$\rho_{p}=$ particle density 


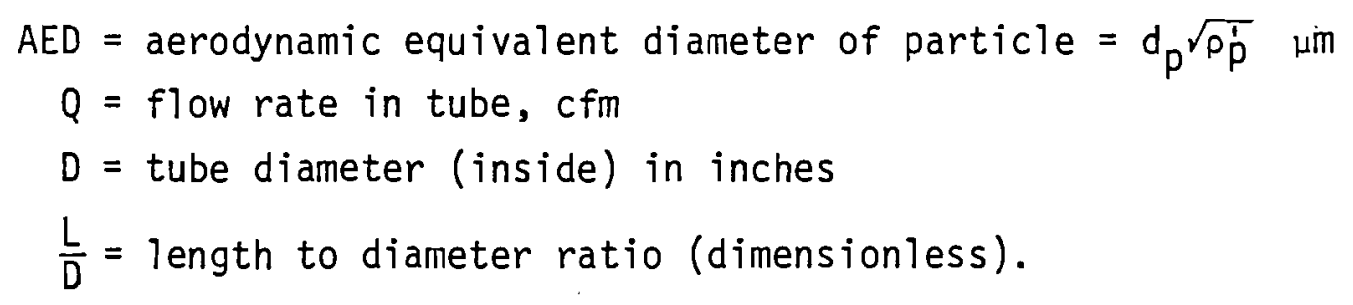

For $Z \leq 0.2$ equation $(A-4)$ is approximated within $2 \%$ by

$$
C / C_{a}=e^{-1.7 Z}
$$

Equation $(A-4)$ is plotted in Figure $A-1$ from which can be calculated the fraction transported through a line for a given value of $Z$ under laminar flow conditions.

For turbulent flow, rigorous analytical solutions to the gravity settling problem are not available. The stirred settling model (which has not been adequately tested) appears to be the best method of estimating gravity settling under turbulent flow conditions. This model assumes "plug" flow and constant remixing, with the particles settling out of a thin stagnant layer near the wall. This model predicts that the ratio of outlet to inlet concentrations for pure gravitational settiing is given by:

$$
C / C_{a}=e^{-A g L *},
$$

where $A_{g}$ is the dimensionless gravitational loss factor given by:

$$
A_{g}=\frac{4}{\pi} \frac{v_{t}}{v_{a}}
$$

and $L^{*}$ is the dimensionless tube length given by:

$$
L^{\star}=L / D \text {, }
$$

for air at typical ambient conditions,

$$
A_{g}=4 \times 10^{-5} \frac{\rho_{p}^{\prime} d_{p}^{2} D^{2}}{Q}
$$

with $D$ in inches, $Q$ in $c f m, d_{p}$ in $\mu m$, and $\rho_{p}^{\prime}$ is the particle specific gravity.

Under turbulent flow conditions, deposition will be enhanced by eddy diffusion and turbulent impaction. Turbulent impaction occurs when particles are thrown against the tube walls by the rapid oscillations in the turbulent flow field. Because of the complexity of turbulent flow, accurate theoretical prediction of rates due to these forces is not presently possible. The following equations have been proposed to correlate the available experimental data on 


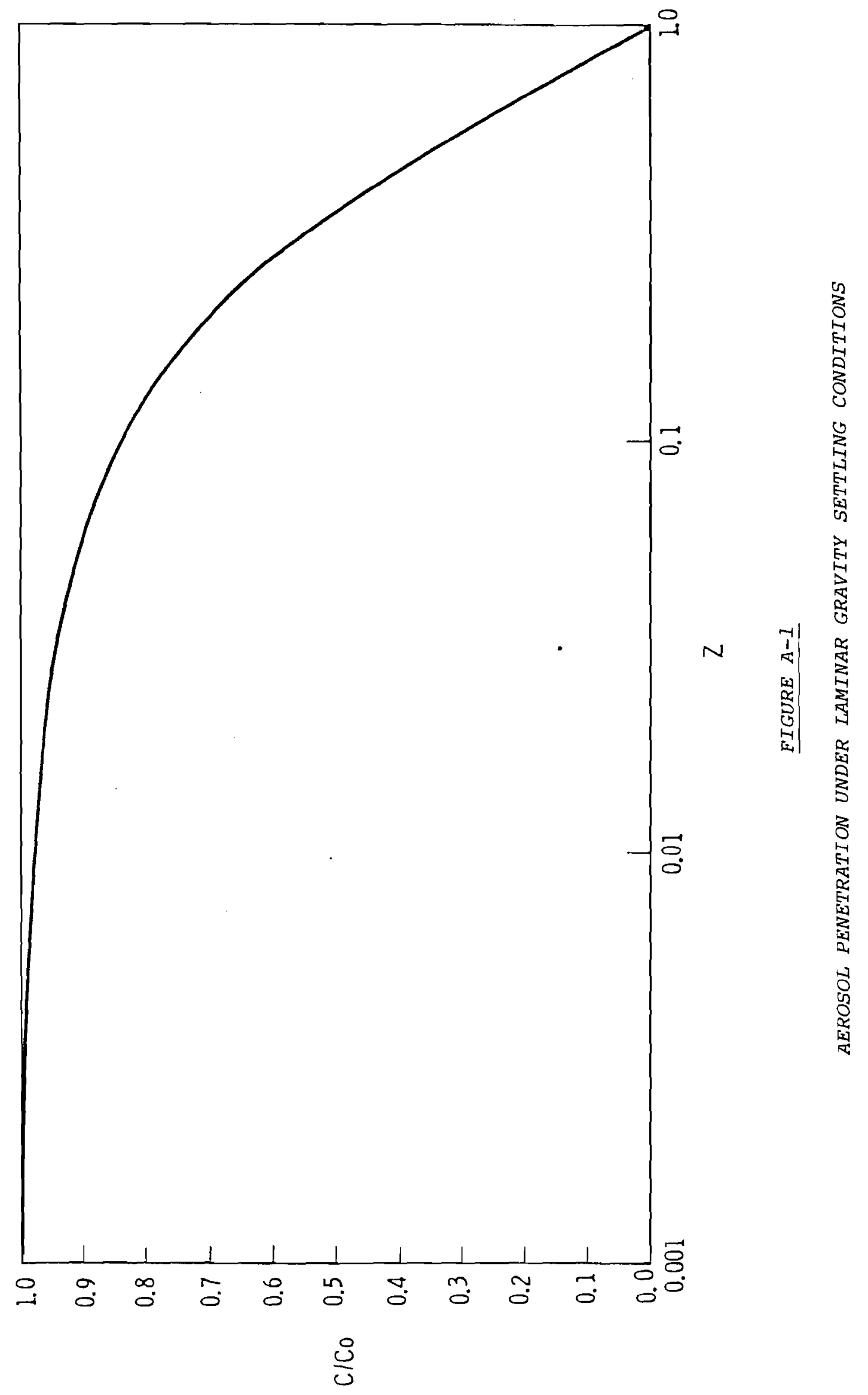


turbulent deposition from air streams flowing in vertical tubes. ${ }^{+}$

$$
\begin{gathered}
A_{t}=1.169 \times 10^{-16} \rho_{p}^{\prime} 1.01 \mathrm{Re}^{2.9} \mathrm{R}^{2.10} \\
C / C_{a}=e^{-A t L^{*}}
\end{gathered}
$$

where $A$ is the dimensionless loss factor and $L^{*}$ is the dimensionless tube length $L / D, \rho_{p}^{\prime}$ is the particle specific gravity, $R$ is the ratio of the particle size in $\mu \mathrm{m}$ and the tube ID in $\mathrm{cm}$, Re is the dimensionless Reynolds number $\left(V_{a} D \rho / \mu\right)$, for air at atmospheric pressure,

$$
\operatorname{Re}=f(T) \frac{Q}{D}
$$

in which

$$
f(T)=\frac{4 \rho_{\text {air }}}{\mu \pi} \text {. }
$$

$Q$ is the flow (cfm), $D$ is the tube ID in inches, and $f(T)$ is given in Table A-II. The Reynolds number can be readily calculated for air at any flow, temperature and tube diameter from the value of $f(T)$.

\section{$\underline{\text { TABLE A-I I }}$}

\section{VALUES OF $f(T)$}

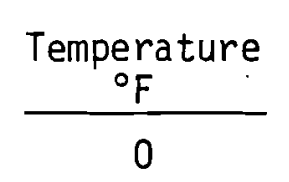

30

60

80

100

150

200

250

$$
\begin{aligned}
f(T)= & \frac{D}{Q} \quad(\operatorname{Re})=\frac{4 \rho_{a i r}}{\mu \pi} \\
& 2.02 \times 10^{3} \\
& 1.79 \times 10^{3} \\
& 1.60 \times 10^{3} \\
& 1.51 \times 10^{3} \\
& 1.41 \times 10^{3} \\
& 1.22 \times 10^{3} \\
& 1.06 \times 10^{3} \\
& 0.93 \times 10^{3}
\end{aligned}
$$

+ This expression was derived by combining expressions for penetration and deposition velocity developed by Sehmel. [7] 
In horizontal tubes both gravity settling and turbulent deposition occur simultaneously. Data are not currently available to predict what the total deposition may be. The most reasonable way to estimate this, then, appears to be simply adding the two effects, i.e.:

and

$$
A(\operatorname{tota} 1)=A_{t}+A_{g}
$$

$$
C / C_{a}=e^{-A(\operatorname{tota} 1) L^{*}}
$$

\section{b. Tube Bends}

In tube bends, deposition may be enhanced somewhat by increased turbulence and by centrifugal forces. Under some flow conditions deposition will be dominated by centrifugal forces. If it is assumed that the flow is constantly remixed and that deposition is caused only by centrifugal forces, the dimensionless loss parameter for bends is given by:

$$
A_{b}=\frac{v_{s b}}{\bar{V}} \frac{4}{\pi}
$$

where $v_{S b}$ is the centrifugal settling velocity and $\bar{V}$ is the average velocity in the bend. The centrifugal settling velocity is similar to the gravity settling velocity except that the acceleration of gravity is replaced by the centrifugal acceleration $\omega^{2} r$ yielding

$$
v_{s b}=\frac{\omega^{2} r\left(\rho_{p}-\rho\right) d p^{2}}{18 \mu}
$$

$\omega=$ angular velocity

$r=$ radius of particle path .

The angular velocity is the particle velocity divided by the particle path radius. Using $\bar{V}$ to approximate the particle velocity, the bend radius, $R_{b}$, to approximate the particle path, and assuming $\rho_{p} \gg \rho$, equation $(A-18)$ becomes

$$
A_{b}=\frac{2}{9 \pi} \frac{\rho_{p} d_{p}^{2} V}{\mu R_{b}} \text { (dimensionless). }
$$

For air at $70^{\circ} \mathrm{F}, 1 \mathrm{~atm}$, and using the tube Reynolds' number this reduces to

$$
A_{b}=6 \times 10^{-7} \frac{\rho_{p}^{\prime} d_{p}^{2} R e}{D R_{b}},
$$


with $d_{p}$ in $\mu \mathrm{m}$, the tube diameter, $D$, in $\mathrm{cm}, R_{b}$ in $\mathrm{cm}$, and $\rho_{p}^{\prime}$ as the particle specific gravity.

The limited experimental data indicates that actual deposition will be larger than predicted by $(A-20)$. The available experimental data covering the range of tube Reynolds' numbers between one thousand and ten thousand are plotted in Figure A-II with equation (A-21) represented by the solid line. This figure rather than equation (A-21) should be used to estimate particle deposition. The dashed 1 ine was used in this report as an estimate. The fraction of particles entering the bend which also passes through is then given by:

$$
C / C_{a}=e^{-A_{b} L^{*}} \text { and } L^{*}=\frac{\pi}{180^{\circ}} \frac{\theta_{b} R_{b}}{D} \text {, }
$$

where $\theta_{b}$ is the angle of the bend in degrees.

c. Other Flow Obstructions

Virtually anything in the delivery line which produces additional turbulence or change of flow direction, can cause additional deposition. Things of this type commonly found in sampling systems include couplings, reducers, expansions, dents or constrictions, rotameters, and tees. Little guidance can be given as to the estimation of deposition in these areas. Every effort should be made to eliminate these sources of deposition from the system.

Non-Uniform Aerosols

All of the preceding relationships given to estimate deposition have been valid for any single given size. Normally aerosols to be sampled will contain a wide spectrum of particle sizes, so that the relationships must be calculated for all sizes in the spectrum and summed to get the total deposition. Typical aerosols are often found to approximate a log-normal size distribution. If the aerosol to be sampled is approximately log-normal the difficulties in estimating the overall deposition are reduced considerably and can be generalized. The relationship between the dimensionless loss factors, $A_{t}, A_{g}, A_{b}$ or $A$ (total) and the penetration concentration ratio for a log-normally distributed aerosol is shown in Figure A-3. If the mass median particle size is used in the relationships for predicting the dimensionless loss factor, Figure A-3 will give the fraction of the total entering particle mass which passes

+ A geometric standard deviation of 2.7 was assumed (a typical value.)

The results are not very sensitive to moderate changes in this parameter. 


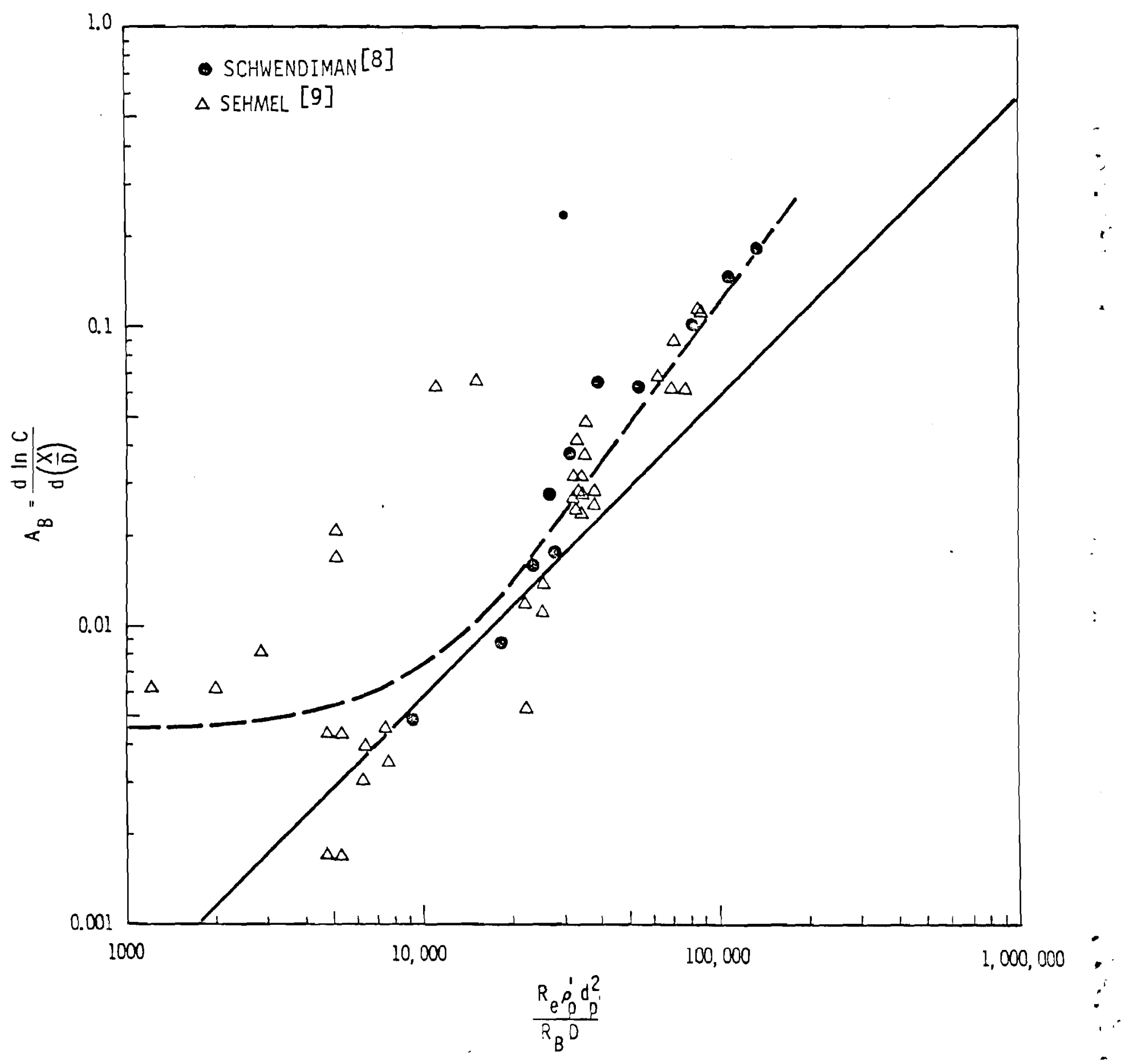

FIGURE A-2

BEND LOSS CORRELATION 


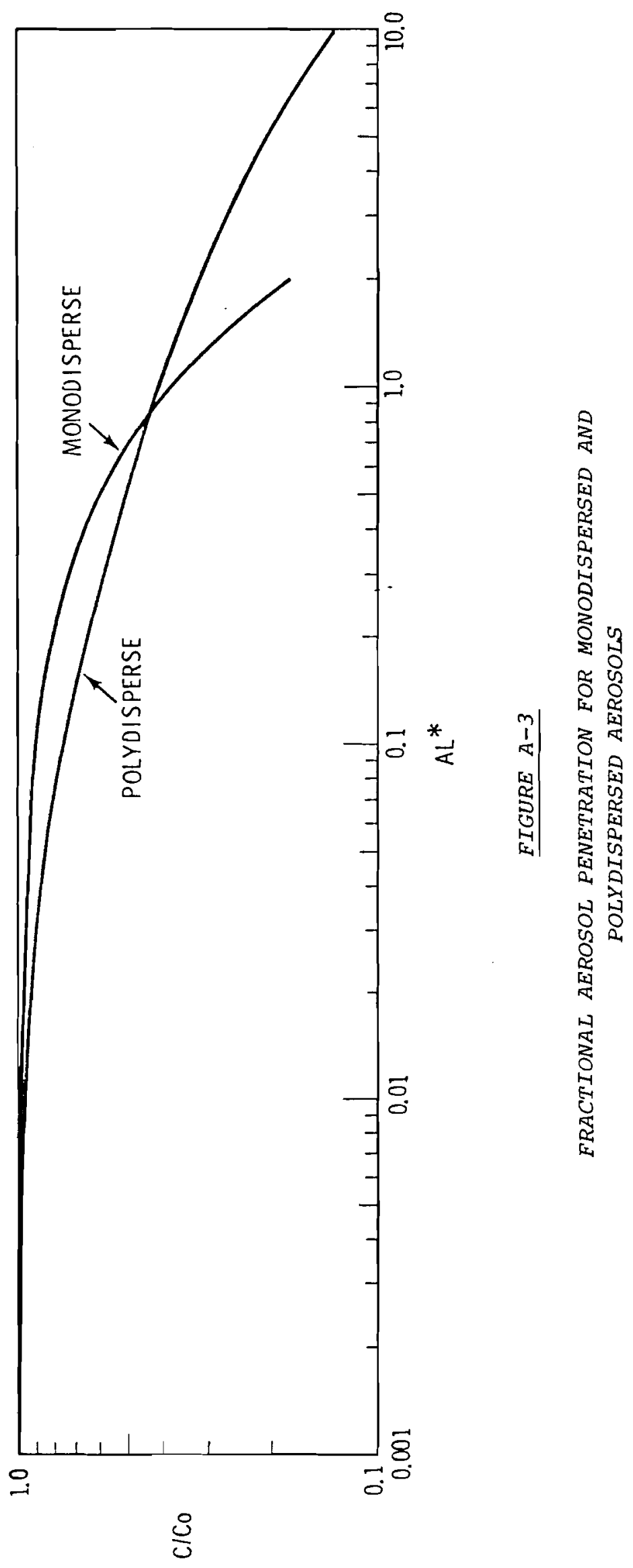


through. If the number median particle size is used the fraction of the total number of particles entering will be found. ${ }^{\dagger}$

Total System Deposition

To estimate the total deposition in a system containing multiple components (i.e., bends, vertical, and horizontal sections), two equivalent methods can be used. Either the separate loss factors $\left(A_{j} L_{j}{ }^{*}\right)$, can be calculated and summed:

$$
A L^{*}\left(\text { Total System) }=\sum \begin{array}{l}
\sum A_{j} L_{j}{ }^{*} \\
\text { components }
\end{array}\right.
$$

and the overall concentration ratio determined from

$$
C / C_{a} \text { (Total System) }=e^{-A L^{*}} \text { (Total System). }
$$

or equivalently the concentration ratios can be determined and the overal1 ratios determined as their product.

$$
C / C_{a}(\text { Total System })=\left(C / C_{a}\right)_{1}\left(C / C_{a}\right)_{2} \cdots\left(C / C_{a}\right)_{n}
$$

In estimating the penetration for a distribution of particle sizes using Figure $A-3$ equation ( $A-23$ ) should first be used to sum the loss factors. The total loss factor is then used in Figure A-3 for determining the estimate.

t The mass median diameter is defined as the diameter for which $50 \%$ of the total mass is in larger particles and $50 \%$ in smaller particles. The number median is the diameter for which $50 \%$ of the particles are larger and $50 \%$ smaller. Obviously the mass median diameter is larger than the number median and may be much larger. 
NOMENCLATURE

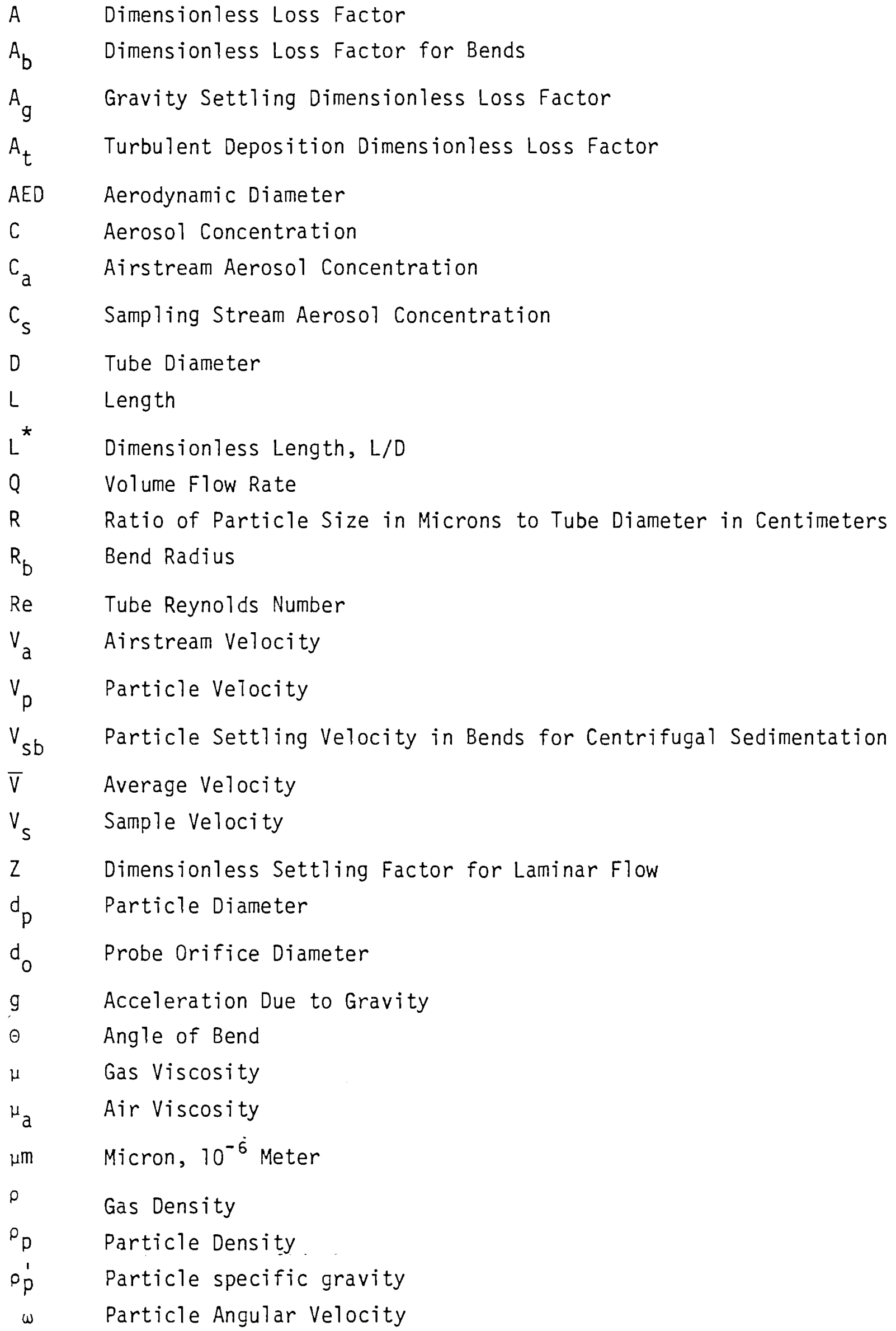


[1] E. Wa]ter. "Zur Probiematik der Entnahmesonden und der Teilstromentauahme fur die Staubbehaltshestimmung in Stromenden Gasen," Staub. Vo1. 53, 1957.

[2] S. Badzioch, "Collection of Gas-Borne Dust Particles By Means of An Aspirated Sampling Nozzle," British Journal of Applied Physics, Vol. 10, January 1959.

[3] R. Dennis, W.R. Samples, D.M. Anderson and L. Silverman. "Isokinetic Sarnpling Probes," Industrial \& Engineering Chemistry, Vo1. 47, No. 2, February 1957, pp. 294-302.

[4] H.H. Watson, "Errors Due to Anisokinetic Sampling of Aerosols," American Industrial Hygiene Association Quarterly, Vo1. 15, March 1954, pp. 21-25.

[5] C.N. Davies, "The Entry of Aerosols into Sampling Tubes and Heads," Brit. J. Applied Physics, Ser. 2, 1 : 921-932. Cited in: T.T. Mercer, Aerosol Technology in Hazard Evaluation, Academic Press, New York, N.Y., 1973, pp 360-361.

[6] J. Pich. Theory of Aerosol Filtration by Fibrous and Membrane Filters, in Aerosol Sciences, edited by C.N. Davies, Chapter IX, Academic Press, London, England, 1966, pp. 277.

[7] G.A. Sehme1, "Particle Deposition from Turbulent Air Flow," Journal of Geophysical Research, Vol. 75, No. 9, pp 1766-1781.

[8] L.C. Schwendiman, G.A. Sehmel, A.K. Postma, "Radioactive Particle Retention in Aerosol Transport Systems", Proceedings of the International Conference on Radioactive Pollution of Gaseous Media, Saclay, France, November 1963, Vol. II, pp. 373.

[9] G.A. Sehme1, "Particle Sampling Bias Introduced by Anisokinetic Sarrpling and Deposition Within the Sampling Line," American Industrial Hygiene Association Journa1, Vo1. 31, November-December, 1970, pp. 758-771. 


\section{DISTRIBUTION}

Off-site

ERDA Chicago Patent Office
9800 S. Cass Ave.
Argonne, I11. 60439
1 A.A. Churm
ERDA, Div. of Safety Standards
$\frac{\text { E Compliance, Wash. D.C. } 20545}{2}$ Edward J. Valario
27 ERDA Technical Information Center

On-Site

ERDA-Richland Office

1 Wayne Lei

Battel1e-Northwest

$\begin{array}{ll}3 & \text { Technical Information Files } \\ 1 & \text { CL Simpson } \\ 1 & \text { RL Conley } \\ 10 & \text { LC Schwendiman } \\ 5 & \text { JM Selby } \\ 1 & \text { J Mishima } \\ 1 & \text { JA GTissmeyer } \\ 1 & \text { GA Sehme1 } \\ 1 & \text { WH Hodgson }\end{array}$

